\title{
Assessment of nicotine dependence symptoms in adolescents: a comparison of five indicators
}

\section{J O'Loughlin, J DiFranza, J Tarasuk, G Meshefediian, E McMillan-Davey, G Paradis, R F Tyndale, P Clarke, J Hanley}

See end of article for authors' affiliations .....................

Correspondence to: Jennifer O'Loughlin, PhD, Direction de santé publique de Montreal-Centre, 1301 Sherbrooke Street East, Montreal, Quebec H2L $1 \mathrm{M} 3$, Canada; jennifer.oloughlin@mcgill.ca

Received 12 March 2002 and revision requested 25 June 2002. Accepted 19 August 2002

\begin{abstract}
Objective: To examine the psychometric properties, test-retest reliability, and convergent construct validity of five indicators of nicotine dependence (ND) symptoms in adolescents.

Design: Analysis of baseline data from a prospective study on the natural history of ND in 1264 adolescents aged 12-13 years.

Setting: Ten Montreal high schools.

Subjects: 233 grade 7 students who had smoked cigarettes one or more times in the three months preceding the baseline data collection.

Main outcome measures: Five indicators of ND symptoms including two that are multi-dimensional (a proxy measure of ICD-10 criteria for tobacco dependence; the Hooked on Nicotine Checklist (HONC)) and three new indicators of "symptom clusters" that emerged from principal component analysis (ND/cravings, withdrawal symptoms, self medication).

Results: All five indicators demonstrated acceptable internal and test-retest reliability. The correlation between the HONC and ND/cravings was 0.910. All other correlations between indicators ranged between $0.716-0.824$. There was considerable overlap in the independent correlates identified for each indicator.

Conclusions: All five indicators performed well psychometrically. Until the meaning, relative importance, and usefulness of each scale is clarified in longitudinal work, decisions regarding which scale(s) are most informative will depend more on the content of the scales, the need for a multi- or unidimensional indicator, and whether or not the scale is theory based.
\end{abstract}

of students. All 13 schools approached agreed to participate; three schools were excluded, two because of a low return rate of consent forms, and one because school administrators could not guarantee cooperation over the entire study. All subjects and a parent/guardian provided signed informed consent. Over half $(56.2 \%)$ of eligible students participated in the baseline data collection; the relatively low response is related in part to the need for blood draws for genetic analysis, and also to a labour dispute in Quebec that resulted in teachers in several schools refusing to collect consent forms.

Baseline data collection in the Fall (autumn) of 1999 comprised questionnaires and standardised anthropometric ${ }^{4}$ and blood pressure measurements. ${ }^{56}$ French or English questionnaires were administered according to the language used in each study school, either classroom by classroom or in the school cafeteria to groups of classes. In one school with 85 subjects, we repeated the baseline questionnaire administration one week later to examine test-retest reliability of the study variables.

The study population for the analyses described in this paper includes the 233 subjects from among the baseline sample of 1264 students, who had smoked one or more times, even just a puff, in the three months preceding the baseline questionnaire (201 of the 233 subjects $(86.6 \%$ ) had smoked one or more times in the past month (that is, were past-month smokers)).

Abbreviations: DSM-IV, Diagnostic and statistical manual of mental disorders, fourth edition; HONC, Hooked on Nicotine Checklist; ICD-10, International statistical classification of diseases and related health problems, 10th revision; ND, nicotine dependence; OR, odds ratio 
Table 1 Questionnaire items and response categories for five nicotine dependence (ND) symptom indicators

\section{Hooked on Nicotine Checklist (HONC)}

1. In the past 3 months, did you seriously try to quit smoking completely and forever? (yes, I quit completely and have remained non-smoking ever since; I never tried to quit; yes, I tried to quit but failed)

2. Do you smoke cigarettes now because it is really hard to quit? (other/I don't know/I smoke so little; I don't know because I have never tried to quit; no; sometimes; often/always)

3a. How physically addicted to smoking cigarettes are you? (not at all, a little, quite, very)

3b. How mentally addicted to smoking cigarettes are you? (not at all, a little, quite, very)

4. Do you ever have strong cravings to smoke cigarettes? (no; not often/not strong; often/not strong or not often/strong; often/strong)

5. How often have you felt like you really need a cigarette? (never, rarely, sometimes, often)

6. Do you find it difficult not to smoke in places where it's not allowed (at a movie theatre, at home if your parents don't know you smoke)? (not at all difficult/I don't know, a bit difficult, very difficult)

Think about the times you have cut down or stopped using cigarettes or when you haven't been able to smoke for a long period (like most of the day). How often did you experience the following . . . ? (never, rarely, sometimes, often)

7. Trouble concentrating

8. Feeling irritable or angry

9. Feeling a strong urge or need to smoke

10. Feeling nervous, anxious or tense

\section{ICD-10 tobacco dependence syndrome}

(1) A strong desire or sense of compulsion to take tobacco: (4 items)

1. Have you ever had strong cravings to smoke cigarettes? (no, yes)

2. How physically/mentally addicted to smoking are you? (not at all addicted, a little addicted, quite addicted, very addicted)

3. How often have you felt like you really need a cigarette? (never, rarely, sometimes, often)

4. Do you find it difficult not to smoke in places where it's not allowed (at a movie theatre, at home if your parents don't know you smoke)? (not at all difficult/I don't know, a bit difficult, very difficult)

(2) Difficulties in controlling tobacco taking behaviour in terms of its onset, termination, or levels of use: (2 items)

1. In the past 3 months, did you seriously try to quit smoking completely and forever? (yes, I quit completely and have remained non-smoking ever since; I never tried to quit; yes, I tried to quit but failed)

2. Do you smoke cigarettes now because it is really hard to quit? (other/I don't know/I smoke so little; I don't know because I have never tried to quit; no; sometimes; often/always)

(3) A physiological withdrawal state when tobacco use has ceased or been reduced, as evidenced by: the characteristic withdrawal syndrome for tobacco; or use of the same (or a closely related) substance with the intention of relieving or avoiding withdrawal symptoms: (4 items)

Now think about the times when you have cut down or stopped using cigarettes or when you haven't been able to smoke for a long period (like most of

the day). How often did you experience the following . . .? (never, rarely, sometimes, often)

1. Feeling irritable or angry

2. Feeling restless/Feeling nervous, anxious or tense

3. Trouble concentrating

4. Feeling a strong urge or need to smoke

(4) Evidence of tolerance, such that increased doses of tobacco are required in order to achieve effects originally produced by lower doses: (2 items) How true are each of the following statements for you?

1. Compared to when I first started smoking, I need to smoke a lot more now to be satisfied. (not at all true, a bit true, very true)

2. Compared to when I first started smoking, I can smoke much more now before I start to feel nauseated or ill. (I've never felt nauseated or ill from smoking, not at all true, a bit true, very true)

(5) Progressive neglect of alternative pleasure or interests because of tobacco use, increased amount of time necessary to obtain or take the substance or to recover from its effects: (4 items)

How true are each of the following statements for you? (not at all true, a bit true, very true):

1. I spend a lot of time getting cigarettes (going out of my way to a store where I know they will sell to me; trying to find someone who will buy them for me)

2. I've stopped hanging out with certain people because of my smoking

3. I avoid going to a friend's house where you're not allowed to smoke even though I might enjoy hanging out with him/her

4. I have cut down or stopped physical activities or sports because of my smoking

(6) Persisting with tobacco use despite clear evidence of overtly harmful consequences, such as depressive mood states consequent to periods of heavy substance use, or drug related impairment of cognitive functioning; efforts should be made to determine that the user was actually, or could be expected to be, aware of the nature and extent of the harm: (2 items)

How true are each of the following statements for you? (not at all true, a bit true, very true):

1. In situations where I need to go outside to smoke, it's worth it even in cold or rainy weather

2. If you are sick with a bad cold or sore throat, do you smoke? (no, I don't have to, I smoke so little; no, I stop smoking when I'm sick; yes, but I cut down on the amount I smoke; yes, I smoke the same amount as when I am sick)

\section{ND/cravings}

1. In the past 3 months, did you seriously try to quit smoking completely and forever? (yes, I quit completely and have remained non-smoking ever since; I never tried to quit; yes, I tried to quit but failed)

2. How often do you have cravings to smoke cigarettes? (never, very rarely, sometimes, often, very often)

3. How physically addicted to smoking cigarettes are you? (not at all, a little, quite, very)

4. How mentally addicted to smoking cigarettes are you? (not at all, a little, quite, very)

5. How often have you felt like you really need a cigarette? (never, rarely, sometimes, often)

6. Do you find it difficult not to smoke in places where it's not allowed (at a movie theatre, at home if your parents don't know you smoke)? (not at all difficult/don't know, a bit difficult, very difficult)

7. If you are sick with a bad cold or sore throat, do you smoke? (no, I don't have to, I smoke so little; no, I stop smoking when I'm sick; yes, but I cut down on the amount I smoke; yes, I smoke the same amount when I am sick)

8. How deeply do you usually inhale the smoke? (into my mouth; into my throat; into my lungs shallow; into my lungs deep)

9. How true is the following statement for you? Cigarettes are good for dealing with boredom (not at all true, a bit true, very true)

10. Do you smoke cigarettes now because it is really hard to quit? (I don't know/I smoke so little/I quit; no, it is not hard to quit; never tried to quit/I don't want to quit; yes (sometimes, often/always))

11. On the days that you smoke, when do you usually smoke your first cigarette of the day? (right when I wake up, in the morning, later or another time) How true are each of the following statements for you? (not at all true, a bit true, very true)

12. I often run out of cigarettes quicker than I thought I would

13. I spend a lot of time getting cigarettes (going out of my way to a store where I know they will sell to me; trying to find someone who will buy them for $\mathrm{me})$

14. I spend a lot of time smoking cigarettes (chain smoking, smoking a lot throughout the day)

15. When you see other kids your age smoking cigarettes, how easy is it for you not to smoke? (very easy, quite easy, a bit difficult, very difficult)

16. How often do you smoke cigarettes when you are alone? (never, sometimes, often/always) 
Table 1 continued

Withdrawal symptoms: Think about the times when you have cut down or stopped using cigarettes or when you haven't been able to smoke for a long

period (like most of the day). How often did you experience the following? (never, rarely, sometimes, often)

1. Feeling irritable or angry

2. Feeling restless

3. Feeling nervous, anxious, or tense

4. Trouble concentrating

5. Feeling a strong urge or need to smoke

6. Trouble sleeping

Self medication: How true are each of the following statements for you? (not at all true, a bit true, very true)

1. I can function much better in the morning after I've had a cigarette

2. When I'm feeling down, a cigarette makes me feel good

3. A cigarette gives me energy when I'm tired

4. Smoking cigarettes calms me down when I feel nervous

5. Smoking cigarettes helps me concentrate on my homework

6. Smoking cigarettes relieves tension when I am stressed

\section{Description of variables}

Sociodemographic data included student's date of birth, sex, language(s) spoken, main language spoken at home, country of birth of each of the student, biologic father and mother, number of years the students has lived in Canada, family composition, and family origin.

\section{Smoking behaviour}

Lifetime smoking history was measured in five items including: (1) Have you ever IN YOUR LIFE smoked a cigarette, even just a puff (drag, hit, haul)? (No; Yes, 1 or 2 times; Yes, 3 or 4 times; Yes, 5 to 10 times; Yes, more than 10 times); (2) Check the one box that describes you best ${ }^{7}$ (I have never smoked a cigarette, even just a puff; I have smoked cigarettes (even just a puff), but not at all in the past 12 months; I smoked cigarettes once or a couple of times in the past 12 months; I smoke cigarettes once or a couple of times each month; I smoke cigarettes once or a couple of times each week; I smoke cigarettes every day); (3) How old were you when you smoked a whole cigarette (down to or close to the filter) for the first time; (4) How old were you when you first took cigarette smoke into your lungs for more than one puff; (5) Have you smoked 100 or more whole cigarettes in your life? (100 cigarettes $=4$ packs of 25) (Yes; No).

Six items measured smoking in the past three months beginning with the month preceding questionnaire administration. ${ }^{8}$ One item for each month measured the number of days on which the subject had smoked during the month, and one item for each month measured the number of cigarettes smoked per day on average (on the days subject had smoked) during that month.

The number of cigarettes smoked during the week preceding questionnaire administration was measured in a seven day recall" (one item). A measure of cigarette "single time exposure" was obtained by asking subjects how much of the cigarette he/she usually smokes (one or a few puffs; less than half of it; about half of it; most of the cigarette; right down to or near the filter; and I don't know (I smoke so little/this does not apply to me)). Finally, students reported how often during the past three months they smoked a cigar or cigarillo, or used chewing tobacco or snuff (never, a bit to try, once or a couple of times a month, once or a couple of times a week, usually every day).

For analysis, data on lifetime smoking history and number of cigarettes smoked in the week preceding baseline data collection were used to create four smoking status categories including "triers" (smoked only once or twice in lifetime), "sporadic smokers" (smoked more than twice in lifetime, but not daily and number of cigarettes smoked per week $\leqslant 1.0$ ), "weekly smokers" (smoked more than twice in lifetime, but not daily, and number of cigarettes smoked per week $>1.0$ ), and "daily smokers" ( smoked every day).
Quit attempts in the past three months were measured in one item: Did you seriously try to quit smoking completely and forever? (Yes, I quit completely and have remained non-smoking ever since; I never tried to quit; Yes, I tried to quit but failed).

\section{ND symptom items}

A total of 46 items that measured numerous diverse ND symptoms in youth were included in the questionnaire, including the 10 items that comprise the Hooked on Nicotine Checklist (HONC).$^{10}$ The remaining items emerged from consultation with seven North American experts on youth smoking, and from six focus groups interviews with teenage smokers aged 14-17 years. ${ }^{11}$ The item specific test-retest reliability and convergent construct validity of many of these items were reported in an earlier study. ${ }^{12}$ In this current study, most items had multi-level response choices.

\section{Other variables}

Tolerance was measured in three items: How true are each of the following statements for you? (not at all true, a bit true, very true): (1) Compared to when I first started smoking, I need to smoke a lot more now to be satisfied; (2) Compared to when I first started smoking, I can smoke much more now before I start to feel nauseated or ill; and (3) I get dizzy or nauseous when I smoke my usual amount of cigarettes.

Depression symptoms were measured in a six item scale that has been previously validated. ${ }^{13-16}$ Subjects reported how often (never, rarely, sometimes, often) in the past three months they: (1) felt too tired to do things; (2) had trouble going to sleep or staying asleep; (3) felt unhappy, sad or depressed; (4) felt hopeless about the future; (5) felt nervous or tense; (6) worried too much about things. Responses were summed to create a depression symptom score (mean $(\mathrm{SD})=2.4(0.7)$; median $=2.3$; Cronbach's $\alpha=0.76$ in past three month smokers). For analysis, scores were categorised into few $(0-1)$, some $(2-3)$, or many $(\geqslant 4)$ depression symptoms.

\section{ND symptom indicators}

We studied five ND symptom indicators, including an existing multi-dimensional measure called the $\mathrm{HONC}^{10}$ an indicator based on the International statistical classification of diseases and related health problems, 10th revision (ICD-10) criteria for tobacco dependence, ${ }^{17}$ and three new ND "symptom clusters" that emerged from principal component analysis of all the ND items in the questionnaire.

The HONC was derived from a theory based definition of $\mathrm{ND}$, which postulates that a person is hooked when they have experienced a loss of autonomy over their use of nicotine. ${ }^{10}$ It includes 10 dichotomous (yes, no) items that assess cravings, 
Table 2 Distribution, internal reliability, and one week test-retest reliability of indicators of nicotine dependence symptoms among grade 7 past three month smokers

\begin{tabular}{|c|c|c|c|c|c|c|c|c|c|}
\hline \multirow[b]{2}{*}{ Indicator* } & \multirow[b]{2}{*}{$\mathrm{n} \dagger$} & \multirow[b]{2}{*}{ Mean $\ddagger$ (SD) } & \multirow[b]{2}{*}{ Median } & \multirow[b]{2}{*}{ Range } & \multicolumn{2}{|c|}{ Internal reliability } & \multicolumn{3}{|c|}{ Test-retest reliability } \\
\hline & & & & & $\mathrm{n} \dagger$ & Cronbach's $\alpha$ & n§̧ & Agreement (\%) & ICC (lower 95\% CI) \\
\hline ICD-10 & 233 & $1.2(1.6)$ & 1.0 & $0-6$ & 183 & 0.91 & 13 & 100.0 & $0.49(\geqslant-0.01)$ \\
\hline HONC & 233 & $4.3(3.4)$ & 4.0 & $0-11$ & 192 & 0.87 & 14 & 78.6 & $0.81(\geqslant 0.51)$ \\
\hline ND/cravings & 233 & $12.0(9.5)$ & 9.6 & $0-38$ & 168 & 0.94 & 12 & NA & $0.91(\geqslant 0.75)$ \\
\hline Withdrawal & 214 & $3.4(4.5)$ & 1.0 & $0-18$ & 206 & 0.88 & 11 & NA & $0.78(\geqslant 0.40)$ \\
\hline Self medication & 209 & $2.3(2.9)$ & 1.0 & $0-12$ & 205 & 0.85 & 9 & NA & $0.74(\geqslant 0.27)$ \\
\hline
\end{tabular}

${ }^{*}$ Analyses were conducted using continuous scores.

†Sample size varied because of missing values.

$\ddagger$ Means were calculated as the total score divided by the sum of the total number of items responded to.

$\S$ Among $n=14$ past three month smokers in one school with 85 subjects.

$\mathrm{Cl}$, confidence interval; HONC, Hooked on Nicotine Checklist; ICC, Intraclass correlation coefficient; ICD-10, International statistical classification of

diseases and related health problems, 10th revision; NA, not applicable; ND, nicotine dependence.

loss of control, withdrawal symptoms, and psychological addiction. In a longitudinal study of adolescents, the endorsement of a single HONC item (indicating diminished autonomy) was associated with a failed attempt at cessation (odds ratio $(\mathrm{OR})=29$ ), continued smoking until the end of follow up $(\mathrm{OR}=44)$, and daily smoking $(\mathrm{OR}=58)$. HONC scores correlated with the maximum amount smoked $(r=0.65)$, and the maximum frequency of smoking $(r=0.79)$. Internal reliability was 0.94 and a one factor solution explained $66 \%$ of the total variance. ${ }^{10}$

For this study, the HONC was modified slightly (table 1). Multiple response choices were provided for each item, allowing that the intensity of symptoms might reflect different degrees of lost autonomy. The question, "Have you ever tried to quit, but couldn't?" was replaced with, "In the past 3 months, did you seriously try to quit smoking completely and forever?" The question, "Have you ever felt like you were addicted to tobacco?" was replaced by two items, "How physically addicted to smoking cigarettes are you?" and "How mentally addicted to smoking cigarettes are you?". All of the items in the modified HONC indicate diminished autonomy over the use of tobacco as defined by the autonomy theory. ${ }^{10}$ Endorsement of any affirmative response category of any HONC item (that is, a positive HONC) was considered to indicate a loss of autonomy. In addition, a continuous HONC score was calculated by summing the scores obtained for each item.

To create an indicator based on the six ICD-10 criteria for tobacco dependence, ${ }^{17}$ ND related questionnaire items were selected to measure each criterion (table 1). An item was con- sidered positive only if the most extreme response choice was endorsed; a criterion was considered positive if the subject endorsed any of its items (the withdrawal syndrome required that two items be endorsed). The subject was categorised as nicotine dependent if he/she met three or more of the six ICD-10 criteria, as defined by ICD-10. In addition, the number of positive criteria was summed to obtain a continuous score of ICD-10 tobacco dependence.

Finally, we used principal component analysis with orthogonal varimax rotation to identify parsimonious clusters of ND symptoms from among the ND items included in the questionnaire. The number of factors selected was based on the scree test and a minimum eigenvalue of 1.0. A factor loading of at least 0.40 was selected as the criterion for determining which items contributed to a given factor. ${ }^{18}$ This analysis resulted in the creation of three new scales (table 1): (1) a 16 item general indicator of ND and cravings; (2) a six item indicator of withdrawal symptoms; and (3) a six item indicator of self medication to alleviate negative affect.

All HONC items, and nine of $16 \mathrm{ND} /$ craving items, overlapped with items in the ICD-10. Seven ND/cravings and HONC items overlapped. Five withdrawal items overlapped with ICD-10 items, and four withdrawal items were also among HONC items. Items comprising the self medication score did not overlap with any items in the other four indicators.

\section{Data analysis}

Internal and test-retest reliability

The internal consistency of the five ND symptom indicators was measured by Cronbach's $\alpha$. Values above 0.85 indicate

Table 3 Mean score of five indicators of nicotine dependence symptoms by smoking status and quit attempts among grade 7 past three month smokers $(n=233)$

\begin{tabular}{|c|c|c|c|c|c|c|c|}
\hline & $\mathrm{n}$ & $\begin{array}{l}\text { Median } \\
\text { cig/week (n) }\end{array}$ & $\begin{array}{l}I C D-10 \\
\text { mean }(S D)\end{array}$ & $\begin{array}{l}\mathrm{HONC} \\
\text { mean (SD) }\end{array}$ & $\begin{array}{l}\mathrm{ND} / \text { cravings mean } \\
\text { (SD) }\end{array}$ & $\begin{array}{l}\text { Self medication } \\
\text { mean (SD) }\end{array}$ & $\begin{array}{l}\text { Withdrawal } \\
\text { mean (SD) }\end{array}$ \\
\hline \multicolumn{8}{|l|}{ Smoking status* } \\
\hline Triers & 65 & 0.0 & $0.3(0.6)$ & $1.6(1.9)$ & $4.1(4.1)$ & $0.4(1.0)$ & $0.8(1.4)$ \\
\hline Sporadic & 68 & 0.0 & $0.6(0.8)$ & $3.6(2.7)$ & $8.6(5.2)$ & $1.4(2.0)$ & 2.3 (3.3) \\
\hline Weekly & 55 & 5.0 & $1.4(1.2)$ & $5.5(2.6)$ & $15.0(6.1)$ & $2.4(2.3)$ & $3.5(3.9)$ \\
\hline Daily & 43 & 30.0 & $3.4(1.9)$ & $8.4(2.4)$ & $25.8(7.0)$ & $5.7(3.2)$ & $8.4(5.2)$ \\
\hline $\mathrm{p}$ Value & & & 0.0001 & 0.0001 & 0.0001 & 0.0001 & 0.0001 \\
\hline$R^{2}, \%$ & & & 50.2 & 49.3 & 66.1 & 41.5 & 35.0 \\
\hline \multicolumn{8}{|l|}{ Quit attempts $\dagger$} \\
\hline Tried, remained non-smoking & 49 & 0 & $0.2(0.6)$ & $2.0(2.3)$ & $5.0(4.2)$ & $1.0(2.0)$ & $1.7(3.0)$ \\
\hline Never tried to quit & 70 & 0 & $0.7(1.4)$ & $4.1(2.9)$ & $11.2(8.7)$ & $1.8(2.8)$ & $2.8(4.4)$ \\
\hline Tried to quit but failed & 91 & 5 & $2.3(1.5)$ & $6.5(3.0)$ & $18.2(8.6)$ & $3.3(3.1)$ & $5.0(4.7)$ \\
\hline $\mathrm{p}$ Value & & & 0.0001 & 0.0001 & 0.0001 & 0.0001 & 0.0001 \\
\hline$R^{2}, \%$ & & & 32.5 & 29.4 & 31.5 & 11.0 & 9.4 \\
\hline Adjusted $R^{2}$ square, \% & & & 49.1 & 50.7 & 65.1 & 37.0 & 30.0 \\
\hline $\begin{array}{l}{ }^{*} n=2 \text { missing. } \\
\dagger n=23 \text { missing. } \\
\ddagger \text { Adjusted for smoking status. }\end{array}$ & & & & & & & \\
\hline
\end{tabular}


Table 4 Correlation* between indicators of nicotine dependence symptoms among grade 7 past three month smokers ( $n=233$ )

\begin{tabular}{lllll}
\hline Indicatort & ICD-10 & HONC & ND/cravings & Self medication \\
\hline HONC & 0.741 & - & & \\
ND/cravings & 0.824 & 0.910 & - & \\
Self medication & 0.716 & 0.733 & 0.755 & - \\
Withdrawal & 0.721 & 0.821 & 0.750 & 0.756 \\
\hline
\end{tabular}

*Pearson product moment correlation coefficients.

†Correlation coefficients were computed using continuous scores.

acceptable internal consistency. ${ }^{19}$ Test-retest reliability was examined in a subsample of past three month smokers from one school with 85 participating students. While patterns of smoking (and hence exposure to nicotine) are likely to be variable in this age group, a lapse of one week for the retest was judged to be optimal to minimise recall bias due to measures being too close in time, and to reduce the likelihood that patterns of smoking had changed substantially over time. We computed the intraclass correlation coefficient ${ }^{20}$; a "reliability of 0.75 is a fairly minimal requirement for a useful instrument". ${ }^{21}$

\section{Convergent construct validity}

Because no gold standard exists against which the criterion related validity of ND measures can be assessed, we examined convergent construct validity in three ways: (1) first, because evidence of convergent construct validity is provided if the indicator examined correlates as expected with other indicators known or thought to be related to the construct under investigation, ${ }^{21}$ we tested the association between each indicator and smoking status, and then quit attempts (both of which are known to be associated with ND, at least in adults ${ }^{22}$; (2) next, we studied the correlation between the five ND symptom indicators; and finally (3) we identified the independent correlates of each ND symptom indicator, from among measures of cigarette exposure and sociodemographic characteristics, in multivariate regression analyses. Similarity in the correlates identified could indicate that the indicators measure similar constructs. The independent correlates of the ICD-10 indicator, dichotomised into tobacco dependent (yes, no), were identified in logistic regression analyses. Scores for the other four indicators were divided into tertiles and independent correlates were identified in polychotomous logistic regression.

\section{RESULTS}

Compared to 992 subjects in the baseline sample who had not smoked in the past three months, a higher proportion of past three month smokers were female $(64.8 \% \quad v \quad 48.9 \%$; $\mathrm{p}<0.0001$ ), they were slightly older (mean (SD) age 12.5 (0.6) years $v 12.2(0.5)$ years; $\mathrm{p}<0.0001)$, there was a much higher proportion of Francophone subjects among past three month smokers $(54.9 \% \vee 25.3 \%$; $p<0.0001)$, and fewer past three month smokers had been born outside Canada $(4.7 \% \mathrm{v}$ $8.4 \% ; p=0.062)$. There was little difference in the proportion of subjects living in single parent families ( $12.5 \%$ of past three month smokers $v 8.6 \%$ of subjects who had not smoked in the past three months, $\mathrm{p}=0.093$ ).

Subjects reported a wide range of smoking experiences: 65 of $233(28.1 \%)$ were triers; $29.4 \%$ were sporadic smokers; $23.8 \%$ were weekly smokers; and $18.6 \%$ smoked daily. The median number of cigarettes smoked per week was l (range 0-121). Triers, sporadic, weekly, and daily smokers smoked a median of $0,0,5$, and 30 cigarettes per week, respectively. Subjects had first inhaled at age 11.3 (1.5) years on average, and this coincided closely with the mean age at which they had first smoked a whole cigarette ( 11.1 ( 1.3 ) years). A total of 140 smokers $(67.0 \%)$ reported recent quit attempts, including $61.2 \%, 65.1 \%, 67.3 \%$, and $76.2 \%$ of triers, sporadic, weekly, and

Table 5 Independent correlates of five indicators of nicotine dependence symptoms among grade 7 past three month smokers $(n=233)$

\begin{tabular}{|c|c|c|c|c|c|}
\hline Independent correlate ${ }^{*}(n)$ & $\begin{array}{l}\text { HONC } \\
\text { OR (95\%Cl) }\end{array}$ & $\begin{array}{l}\text { ND/cravings } \\
\text { OR (95\%CI) }\end{array}$ & $\begin{array}{l}\text { ICD-10 } \\
\text { OR }(95 \% \mathrm{Cl})\end{array}$ & $\begin{array}{l}\text { Self medication } \\
\text { OR }(95 \% \mathrm{Cl})\end{array}$ & $\begin{array}{l}\text { Withdrawal } \\
\text { OR (95\%Cl) }\end{array}$ \\
\hline \multicolumn{6}{|l|}{ Sex } \\
\hline Male (82) & Ref & $-\dagger$ & - & Ref & Ref \\
\hline Female (151) & 2.8 (1.4 to 5.4$)$ & & & $2.4(1.2$ to 4.8$)$ & $2.3(1.1$ to 4.6$)$ \\
\hline \multicolumn{6}{|l|}{ Number of cigarettes in past week } \\
\hline $0(110)$ & Ref & Ref & Refł & Ref & Ref \\
\hline$\leqslant 1-6(64)$ & $2.6(1.2$ to 5.6$)$ & 2.2 (1.0 to 4.7$)$ & 5.5 (1.8 to 17.2$)$ & $2.0(0.9$ to 4.3$)$ & 2.7 (1.2 to 6.1$)$ \\
\hline$\geqslant 7(59)$ & $10.9(4.1$ to 28.9$)$ & $19.7(6.5$ to 59.4$)$ & $19.5(5.4$ to 69.8$)$ & $5.2(2.0$ to 13.4$)$ & 3.1 (1.2 to 8.2$)$ \\
\hline \multicolumn{6}{|l|}{ Chew tobacco } \\
\hline No (205) & - & - & - & - & Ref \\
\hline Yes (16) & & & & & 7.8 (2.0 to 29.6$)$ \\
\hline \multicolumn{6}{|l|}{ Depression symptoms } \\
\hline Few (64) & Ref & Ref & - & Ref & Ref \\
\hline Some (118) & 2.7 (1.3 to 5.7$)$ & $2.1(1.0$ to 4.4$)$ & & 3.1 (1.4 to 6.7$)$ & $6.6(2.9$ to 15.3$)$ \\
\hline Many (51) & $4.8(1.8$ to 12.5$)$ & 2.6 (1.0 to 6.8$)$ & & $7.2(2.6$ to 19.5$)$ & $17.2(5.9$ to 50.1$)$ \\
\hline \multicolumn{6}{|l|}{ Age smoked whole cigarette, y } \\
\hline Don't know (59) & - & Ref & - & Ref & - \\
\hline $11-13(126)$ & & $2.7(1.1$ to 7.1$)$ & & $3.4(1.1$ to 10.4$)$ & \\
\hline$\leqslant 10(48)$ & & $3.2(1.0$ to 10.4$)$ & & $5.4(1.4$ to 20.5$)$ & \\
\hline \multicolumn{6}{|l|}{ How much of the cigarette is smoked } \\
\hline One or few puffs/don't know (78) & Ref & Ref & - & Ref & Ref \\
\hline Less than half/about half (31) & $1.3(0.5$ to 3.4$)$ & $1.6(0.6$ to 4.3$)$ & & $2.3(0.8$ to 6.4$)$ & $1.6(0.6$ to 4.4$)$ \\
\hline Most/all (109) & $4.6(2.0$ to 10.4$)$ & $3.6(1.4$ to 8.8$)$ & & 3.6 (1.4 to 9.1$)$ & $3.2(1.3$ to 7.7$)$ \\
\hline \multicolumn{6}{|l|}{ Need to smoke more now to be satisfied } \\
\hline Not at all true (133) & Ref & Ref & Ref & Ref & Ref \\
\hline A bit true/very true (75) & $5.6(2.6$ to 12.3$)$ & $8.6(3.6$ to 20.6$)$ & $24.4(6.5$ to 92.0$)$ & 3.5 (1.7 to 7.5$)$ & $5.3(2.4$ to 11.7$)$ \\
\hline \multicolumn{6}{|c|}{ Need to smoke more now to feel nauseated or ill } \\
\hline Not at all true (144) & - & - & - & - & Ref \\
\hline A bit true/very true $(56)$ & & & & & $2.2(1.1$ to 4.6$)$ \\
\hline
\end{tabular}

*In each model, the independent correlate predicts the risk of having more ND symptoms.

†Not significant.

$\ddagger$ Due to zero cells, the number of cigarettes smoked in the past week was categorised as $0-6,7-24$, and $\geqslant 25$. 
daily smokers, respectively. Among those who attempted to quit, 35.0\% remained non-smoking (up until the current data collection), including $46.9 \%, 34.9 \%, 5.5 \%$, and $2.4 \%$ of triers, sporadic, weekly, and daily smokers, respectively. According to our proxy ICD-10 measure, $17.3 \%$ of past three month smokers were tobacco dependent. Tobacco dependence increased notably with increased exposure to cigarettes, such that $0 \%$, $1.5 \%, 18.2 \%$, and $67.4 \%$ of triers, sporadic, weekly, and daily smokers, respectively, were tobacco dependent. Finally, $85.2 \%$ had a positive HONC including $61.5 \%, 89.7 \%, 100.0 \%$, and $100.0 \%$ of triers, sporadic, weekly, and daily smokers, respectively.

\section{Psychometric properties}

Table 2 describes the distributions of the scores on each ND symptom indicator. All five ND symptom indicators demonstrated acceptable internal reliability and test-retest reliability.

\section{Convergent construct validity}

In univariate analyses, scores for each of the five ND indicators all increased with increased exposure to tobacco, and in addition could differentiate subjects who had tried to quit and failed, from those who had tried and remained non-smoking (table 3 ). The $\mathrm{ND} /$ cravings indicator, and the HONC, were highly correlated with each other; the correlations between the other indicators ranged between 0.716-0.824 (table 4). The independent correlates of the five indicators overlapped considerably: number of cigarettes smoked in the past week and the tolerance symptom, "need to smoke more now to be satisfied", emerged strongly and consistently across all five models; depression symptoms and how much of the cigarette smoked were significant in four of the five models; and sex was significant in three of the five models (table 5). The finding that fewer correlates were identified in the ICD-10 model possibly reflects that the dependent variable was dichotomous.

\section{DISCUSSION}

ND has been defined as the compulsive use of cigarettes to achieve pleasurable and other effects and to avoid withdrawal symptoms. ${ }^{23}$ According to the Diagnostic and statistical manual of mental disorders, fourth edition (DSM-IV), ${ }^{24}$ symptoms of ND include tolerance, withdrawal symptoms, use in larger amounts and over longer periods than intended, a persistent desire or unsuccessful attempts to cut down or control usage, a great deal of time spent in use related activities, social disruption caused by use, and continued use despite physical or psychological symptoms. Symptoms of nicotine withdrawal include dysphoria or depressed mood, insomnia, irritability, frustration or anger, difficulty concentrating, restlessness, decreased heart rate, and increased appetite, and cravings. ${ }^{22}$ However, these definitions remain controversial, even in adults. For example, cravings are not included in the DSM-IV criteria, but are included in the ICD-10 criteria for tobacco dependence, ${ }^{17}$ and the role of tolerance in ND is debated. ${ }^{25} 26$

In this analysis, all five indicators of ND symptoms demonstrated convergent construct validity against quit attempts and smoking status; all five were highly intercorrelated (in part because of the shared items); and there was considerable overlap in their independent correlates. Since the individual items comprising each indicator were developed based on expert opinion or qualitative inquiry among adolescents, these indicators also possess content validity. This analysis therefore cannot distinguish between these five indicators on the basis of psychometric performance or convergent construct and content validity. It could be that, in spite of their obvious content differences, all are relatively good indicators of ND symptoms, at least cross sectionally. This would be true if ND is indeed a multidimensional phenomenon that includes symptoms of withdrawal, self medication, cravings, and loss of

\section{What this paper adds}

Few studies have examined the natural history of nicotine dependence (ND), in part because there is no widely accepted, theoretically derived, and psychometrically sound tool to measure ND in adolescents. This article compares the psychometric properties of five indicators of ND symptoms, including the multidimensional Hooked on Nicotine Checklist, an indicator based on the ICD-10 criteria for tobacco dependence, and three new ND "symptom clusters" measuring ND/cravings, withdrawal symptoms, and self medication to alleviate negative affect. All five indicators performed well psychometrically. Until the meaning, relative importance, and usefulness of each scale is clarified in longitudinal work, decisions regarding which scale is most useful in a given context will depend on its content, the need for a multi- or unidimensional indicator, and whether or not the scale is theory based.

autonomy. However, until the meaning, relative importance, timing of appearance, and usefulness of each indicator is clarified in longitudinal work, decisions regarding which scale(s) are most useful for a particular research project will depend on the context and objectives of the research, as well as the content of the scales, the need for a multi- or unidimensional indicator, and whether or not the scale is theory based.

\section{Limitations}

These data were drawn from a convenience sample of grade 7 students (age 12-13 years), and are therefore not representative of the general population. However, the sample included adolescent smokers with a wide range of cigarette exposures. Range of exposure is arguably more important in a study examining reliability and validity, than the representativeness of the population. In addition, if the biological processes underlying the development of ND do not differ substantially between populations, then representativeness is not crucial in a measurement study.

The sample size of smokers was relatively small, but did not impede multivariate analysis, or result in overly wide confidence intervals or difficulties attaining statistically significant results. Finally, the sample included only smokers in early adolescence. It could be that the constellation of ND symptoms as well as the timing of the appearance of individual symptoms or symptom clusters differ in different age groups.

\section{Conclusion}

All five ND indicators showed satisfactory psychometric properties and in addition were related as expected to other variables thought to be associated with ND. As such they each provide an informative measure for use in descriptive, analytic, or evaluative research on nicotine dependence in adolescence. However, until the meaning, relative importance, and usefulness of each scale in predicting failed cessation, continued smoking, or progression to higher levels of smoking is clarified in longitudinal work, decisions regarding which scale(s) to use will depend more on the content of the scales, the need for a multi- or unidimensional indicator, and whether or not the scale is theory based.

\section{ACKNOWLEDGEMENTS}

This research was funded by the National Cancer Institute of Canada, with funds from the Canadian Cancer Society. Jennifer O'Loughlin was a Research Scholar of the Fonds de la recherche en sante du Quebec when this work was completed and is currently an Investigator of the Canadian Institutes of Health Research. Paul Clarke is a Research Scholar of the Fonds de la recherche en santé du Québec (FRSQ). 
Rachel Tyndale acknowledges the support of a Canadian Research Chair in Pharmacogenetics. The authors are grateful to the school administrators, teachers, and students who participated.

\section{Authors' affiliations}

*J O'Loughlin, *G Paradis, J Hanley, Department of Epidemiology, McGill University, 1020 Pine Avenue West, Montreal, Quebec H3A 1A2, Canada

J DiFranza, Department of Family Medicine and Community Health, University of Massachusetts Medical School, 55 Lake Avenue, Worcester, Massachusetts 01655, USA

J Tarasuk, G Meshefediian, E McMillan-Davey, Direction de santé publique de Montréal-Centre, 1301 Sherbrooke Street East, Montreal, Quebec H2L 1M3, Canada

R F Tyndale, University of Toronto, Department of Pharmacology and Centre for Addictions and Mental Health, 1 King's College Circle, Room 4336 MSB, Toronto, Ontario M5S 1A8, Canada

P Clarke, Department of Pharmacology and Therapeutics, McGill

University, 3655 Drummond Street, Room 1325, Montreal, Quebec H3G

1Y6, Canada

*Also Direction de santé publique de Montréal-Centre

\section{REFERENCES}

1 US Department of Health and Human Services. Preventing tobacco use among young people. A report of the Surgeon General, 1994. Atlanta, Georgia: Public Health Service, Centers for Disease Control and Prevention, Office on Smoking and Health, 1994. (US Government Printing Office Publication No S/N 017-001-00491-0.)

2 Difranza JR, Rigotti NA, McNeill AD, et al. Initial symptoms of nicotine dependence in adolescents. Tobacco Control 2000:9:313-19.

3 Colby SM, Tiffany ST, Shiffman S, et al. Measuring nicotine dependence among youth: a review of available approaches and instruments. Drug Alcohol Depend 2000;59(suppl 1):S23-39.

4 Evers SE, Hooper MD. Dietary intake and anthropometric status of 7 to 9 year old children in economically disadvantaged communities in Ontario. J Am Coll Nutr 1995;14:595-603.

5 Park MK, Menard SM. Accuracy of blood pressure measurement by the Dinamap monitor in infants and children. Pediatrics 1998:8:308-18.

6 Luepker RV, Perry CL, McKinlay SM, et al. Outcomes of a field trial to improve children's dietary patterns and physical activity. JAMA 1996;275:768-76.

7 Flynn BS, Worden JK, Secker-Walker RH, et al. Prevention of cigarette smoking through mass media intervention and school programs. Am J Public Health 1992;82:827-33

8 Centers for Disease Control and Prevention. Selected cigarette smoking initiation and quitting behaviors among high school students . United States, 1997. MMWR Morb Mortal Wkly Rep 1998;47:386-9.
9 Stephens T, Morin M, eds (Health Canada). Youth Smoking Survey, 1994: Technical Report. Ottawa: Minister of Supply and Services Canada, 1996. (Catalogue No. H49-98/1-1994E).

10 DiFranza JR, Savageau JA, Fletcher K, et al. Measuring the loss of autonomy over nicotine use in adolescents: the DANDY study. Arch Pediatr Adolesc Med 2002; 156:397-403.

11 O'Loughlin J, Kishchuk N, DiFranza JR, et al. The hardest thing is the habit: a qualitative investigation of adolescent smokers' experience of nicotine dependence. Nicotine Tobocco Research 2002;4:201-9.

12 O'Loughlin J, Tarasuk J, Difranza JR, et al. Reliability of selected measures of nicotine dependence among adolescents. Ann Epidemiol 2002; 12:353-62.

13 Choi WE, Peirce JP, Gilpin EA, et al. Which adolescent experimenters progress to established smoking in the United States. Am J Prev Med 1997; 13:385-91.

14 Zhu S, Sun J, Billings SC, et al. Predictors of smoking cessation in US adolescents. Am J Prev Med 1999;16:202-7.

15 Escobedo LG, Reddy M, Giovino GA. The relationship between depressive symptoms and cigarette smoking in adolescents. Addiction 1998;93:433-40.

16 Kandel DB, Davies M. Epidemiology of depressive mood in adolescents. Arch Gen Psychiatry 1982;39:1205-12.

17 World Health Organization. International statistical classification of diseases and related health problems, 10th revision. Geneva: WHO, 1992.

18 Hatcher L, Stepanski EJ. A step-by-step approach to using the SAS system for univariate and mulitvariate statistics, 4th ed. Cary, North Caroline: SAS Institute Inc, 1994.

19 McDowell I, Newell C. Measuring health: a guide to rating scales and questionnaires. New York: Oxford University Press, 1996.

20 Fisher RA. On the "probable error" of a coefficient of correlation deduced from a small sample. Metron 1921:1:1-32.

21 Streiner DL, Norman GR. Health measurement scales. A practical guide to their development and use, 2nd ed. New York: Oxford University Press, 1996.

22 US Department of Health and Human Services. The health consequences of smoking: nicotine addiction. A report of the Surgeon General, 1988. Rockville, Maryland: Public Health Service, Centers for Disease Control, Office on Smoking and Health, 1988. (DHHS Publication No (CDC) 88-8406.)

23 Rojas NL, Killen JD, Haydel KF, et al. Nicotine dependence among adolescent smokers. Arch Pediatr Adolesc Med 1998;152:151-6.

24 American Psychiatric Association. Diagnostic and statistical manual of mental disorders: DSM-IV, 4th ed. Washington DC: American Psychiatric Association, 1994.

25 Robinson TE, Berridge KC. The neural basis of drug craving: an incentive-sensitization theory of addiction. Brain Res Rev 1993; 18:247-91

26 Fagerstrom KO, Heatherton TF, Kozlowski LT. Nicotine addiction and its assessment. Ear Nose Throat J 1990;69:763-6.

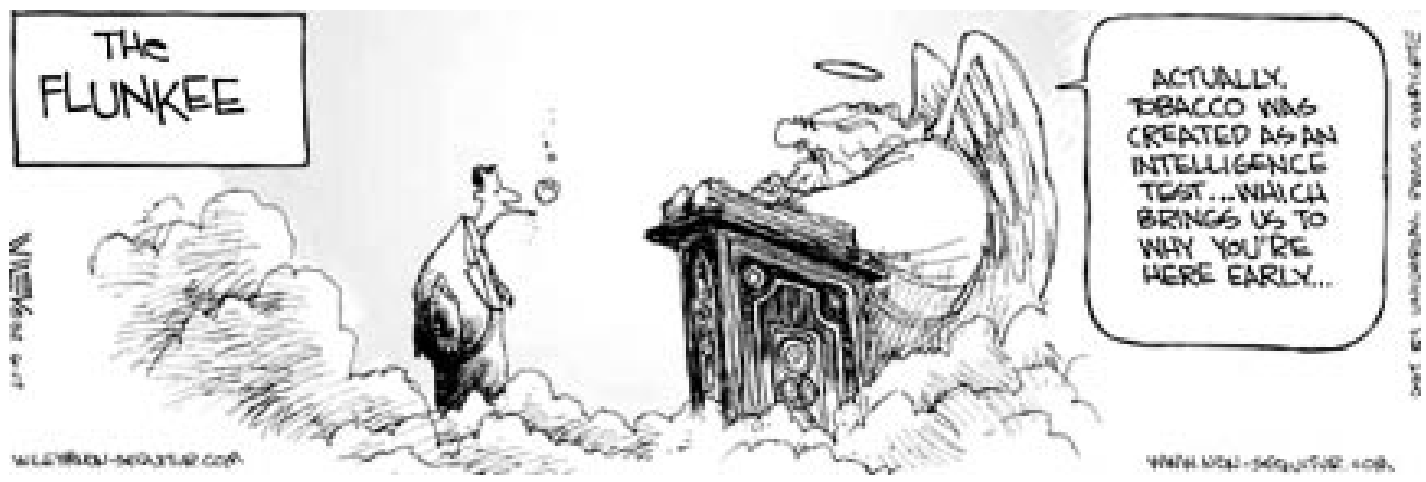

CNon Sequitur. The Flunkee by Wiley, 17 June 2002. 